\title{
EDUCATION AS AN ELEMENT ENHANCING INDIVIDUAL AND COLLECTIVE AWARENESS OF THE NEED TO PRESERVE THE ENVIRONMENT
}

\author{
Livia Durac ${ }^{1}$ \\ Keywords: formal education, informal education, environmental protection
}

\begin{abstract}
An undeniable reality nowadays, with an array of phenomena that affects areas that are not traditionally characterised by favourable conditions for unexplainable climate manifestations, is one of the most serious challenges for the present state of evolution.

The degree of "newness" of atmospheric processes that occur with a worrisome frequency and intensity is no longer just a subject "among others", but it must be on top of the list of pressing issues. Solving it has become imperative, since it is an absolute condition for the continuation of our species.

In the category of measures that have the potential to level up the winding path towards finding solutions for the issue of environmental dynamics, mainly atmospheric ones, education comes first. The connection between the care for the environment and the accentuated violence (in the last decades) of climate changes is not new. The need for man's timely intervention towards reducing the risks generated by the decades of indifference towards the environment has gained an undoubtedly high price that must be discounted as soon as possible.

The purpose of this article is to stress the role of education - both formal and informal - in promoting, making aware, and implementing means of real protection for the environment where humankind lives.
\end{abstract}

\section{INTRODUCTION}

As a present imperative, the process of awareness of the need to protect the environment has shaped up into an actual ideology that implies man's responsibility to respect, protect, and preserve for future generations a space for existence, purified of the consequences of decades of perpetual indifference. Anchoring this space into the idea of unlimited potential, or of a level of unlimited sustainability, has reached its highest point, activating the alert button at a global level - with regards to the fragile balance to which our planet and its populating beings have been confined.

\footnotetext{
${ }^{1}$ PhD Professor, “Petre Andrei” University, Iasi, liviadurac@yahoo.com
} 
Approximately 15-20 years ago, specialists' warnings with regards to such phenomena as the melting of icebergs, caused by the greenhouse effect, or the extinction of species as a result either of massive deforestations, streaming from man's wish to occupy new spaces, or of chemical discharge into the sea/ocean waters - to provide a few short examples - had a small impact on their addressees, or were often seen as superfluous or categorised "among others". Much to the despair of nowadays people, drawn towards excessive consumerism to the detriment of the planet, the boomerang effect of our own actions is more and more acutely felt, inevitably fading away humankind's ontological horizon.

At an atmospheric level, manifestations occurred that were until recently thoroughly unusual for one area or another, with a frequency and intensity that tested both human and material resilience to their limits.

In terms of effects, pollution is the phenomenon that prevails both on the environment and on its source: man.

Such an existential context attacked, on the one hand, by the consequences of an insufficient awareness of the inevitable dangers deriving from ignorance, respectively from the ever more exaggerated needs of man, require a thorough reconfiguration of the issue of environmental protection, which would operate at the level of collective awareness. In this sense, we consider that the main way through which we can raise collective awareness is education delivered at a formal as well as informal level.

A swift and efficient switch to concrete and extended actions is the fundamental challenge for specialists, and also for everyone.

\section{PSYCHOLOGICAL PERSPECTIVES ON EDUCATION IN MAKING CHILDREN AWARE WITH ENVIRONMENTAL CONCERN}

As part of a process that starts from the early years of age and which - one way or another - continues throughout our lifetime, education for the protection of the environment engages people in actions meant to make them understand the meaning of their personal and collective contribution to the activity of preserving the environment. In this line of ideas, analysing childhood, when several complex psycho-cognitive acquisitions take place (language, thought, memory, consciousness, will, attention, motivation, affection), allows understanding the correspondences between the respective processes and elements on which we can base our understanding of the issue of environmental protection, respectively acquiring the habits and knowledge that are needed in order to attain this objective.

According to the EPA (Environmental Protection Agency), the constitutive elements of environmental education are: (i) awareness and sensitivity towards the environment and its related challenges; (ii) knowledge and understanding of the environment and its challenges; (iii) concern towards the environment and 
motivation to improve or preserve its quality; (iv) ability to identify and help solve environmental challenges; (v) involvement in activities leading to solving environmental challenges.

The psychological perspective associates with the term awareness, a human specificity by excellence, certain functions - cognitive, projective, anticipative and regulative - which, through their contents, resonate with the first of the constitutive elements of environmental education. Thus, the cognitive function is linked to selfknowledge as well as to knowledge of the world, the projective function is concerned with directing activity to the purpose of transforming reality, the anticipative function can be related to one's ability to pre-establish a certain flow of events, to one's prevision (more or less exact) of their results, and the regulative function translates into controlling consciousness with regards to the way of performing an action, in the sense of establishing a connection between the respective action and the intended purpose/objective.

For example, within the family, the child observes the actions of his parents / older siblings directed towards a certain behaviour - favourable or negative, as the case may be - in relation to the way of preserving a well-kept space. In the language development stage, the child is transmitted / explained the specific rules (the cognitive function), and thus (s)he becomes able to apply them (the projective function). Also, through exercise / repetition, the child grows to know that (s)he will be appreciated / praised if (s)he obeys the commands from the family members to put away their belongings / toys after playing with them, to become involved in various domestic activities that they can handle (the anticipative function). In the same context, the child develops habits, skills, since their actions imply a high level of attention, inherent for any beginning (the regulative function).

The second component correlates to a great extent with the dimension awareness, to which we can add one of the important operations of thought: understanding - as a result of the thought process.

The concern towards the environment and the motivation to improve or preserve its quality can be related to one of the principles of motivation, homeostasis, in virtue of which, besides the basic needs (implied by this principle), man strives for stability, balance - including in relation to esthetical needs internal harmony, spiritual peace, and pleasure. Thus, from the perspective of a certain relation with the surroundings, respectively of esthetical and functional criteria, which bring balance and eventually a pleasant state for the individual, irrespective of age, the environment is an influent resort.

The last of the four constitutive elements of education towards environmental protection can be based on a phenomenon with a significant role in the dynamics of human psychological processes: will. For the child, the voluntary act, often based on motivation, is eventually a pre-condition for applying both the actions noticed in 
adults / older siblings and the encouragements that give direction to their behaviour.

All these psychological coordinates are important in the becoming of a person and build up a favourable framework for the child to assimilate the set of norms and behavioural norms that will be transmitted through formal and informal education; a cumulus of information needed to create an elementary level of knowledge of the need to protect the environment.

\section{EDUCATION FOR ENVIRONMENTAL PROTECTION IN A FORMAL EDUCATIONAL CONTEXT}

As an extended process that stimulates engaging individuals in finding the appropriate solutions to environmental issues and actually taking action, education focusing on meeting this objective supports the individual in developing a deep understanding of environmental issues, in the direction of their correct information and adopting responsible decisions. The complexity of this type of education comes from the fact that it does not indicate a specific action method, but it rather directs the individual towards a series of challenges, inviting them to identify, through critical evaluation processes, their own solutions, thus facilitating their decision-making skills. Practically, irrespective of its constitutive elements that draw our attention, we can notice that the natural world is a subject for study by excellence: from the quality of water, the chemical composition of the air (altered by household or industrial pollution, or by pollution caused by the means of transportation), to acid rains, vegetation fires, massive deforestations, all improperly directed residual elements, genetically modified foods, overpopulation, etc. The study field is eminently inexhaustible, as one cause derives from another, which in its turn leads to a new one, ad infinitum. One efficient method to analyse such aspects requires keeping them in plain focus, by implementing measures such as adapting the school curriculum to the requirements imposed by the current context - an important imperative of present times.

In 1990, EPA established the following action directions for the Office of Environmental Education: (i) enhance public knowledge and awareness with regards to environmental issues; (ii) teach critical thinking; (iii) individually develop problem-solving and decision-making skills; (iv) not settling with one particular viewpoint.

The most important component, on which both formal and informal environmental education is based, is awareness of the importance of promoting it. In terms of influence, humankind's need to connect with the environment is similar to the need for socialisation, in the idea of natural evolution.

The need for cooperation between formal and informal education is supported by Y.J. Dori and R. Tal (2000), who believe that, by combining the two, teachers 
have the advantage of presenting a more detailed image of the complexity of the issues in the real world.

Referring to the awareness component, some specialists (Dolan, Nichols, \& Zeigler, 2009) focus on its connection with perceptual changes, which generate changes at a behavioural and attitudinal level, as well as from the perspective of the ethical and moral value system. Or, placing an accent on training students mainly from the perspective of acquired contents, which must be as vast as possible, and not enough on actions meant to stimulate the child's care towards the environment, cannot seize the dynamics of the relationship between educational sciences and environmental education.

In the context of formal education, validating the statement that learning is a natural activity is an indication of its objective, which, according to J. Heimlich (1993), is to enhance investigation, one's epistemic curiosity. The author also presents the idea that the success of an educational path focused on environmental issues depends on the way in which the respective programme resonates with the interests, wishes and concerns of the people registered in the programme, rather than with the way in which their needs and wishes are seen by the organising institution or by a certain trainer.

An inevitable nowadays phenomenon, technological progress generates the imperative need to change the educational system with the purpose of training new generations in the spirit of care towards the environment. It is no less true that, for a child raised in modern society, their relationship with the environment is - in the best case - placed under a question mark, because of the speed with which technology penetrates the most hidden depths of human beings: interests, affection, relations, a continuously unquenchable state of meeting the various needs / wishes, (though) often short-lived. In this idea, the trainers' mission becomes all the more difficult from the perspective of rediscovering the authenticity of the connection between individual and nature, of cultivating respect and responsibility towards it.

Raising a certain level of understanding in environmental protection, acquired through formal education, can contribute to a great extent to developing awareness with this issue. In other words, it can be difficult or even discouraging for some students, in a certain educational stage, to show sudden interest with concerns that are specific to environmental protection, in the absence of a foundation built $a$ priori.

Another factor that conditions the interest towards acquiring knowledge, which activates entrepreneurship, acting as a mobiliser, is the direct link between people and their natural space per se. Some authors (Hadzigeorgiou and Stivaktakis, 2008; Pugh, 2004) are concerned with separating these plans: (i) participating in the learning activity and (ii) the direct connection with the study field, respectively (i) the distinction between elements such as humour, interaction 
with the others, exhibitionist behaviours versus (ii) engagement in scientific contents, concluding without hesitation that the level of awareness is likely high and well developed when the trainees are authentically connected to the natural world, as an inherent part of their field of study. Only this way, meaning seeing the natural world as a field of study, could the trainees feel motivated to study it. Thus, the distribution into disciplines of study within the school curriculum, allocating material and human resources in the same way as in the case of any other field, with the purpose of obtaining results with an influence on school performance as a whole, generating motivation.

Some authors identify a certain level of disconcertion between educational sciences and environmental education. Thus, in his study Science: An unreliable friend to environmental education?, Martin Ashley (2000) refers to the nature of the relation between the two fields, pleading in favour of the idea that, although science justifies enough the need to adopt procedures and measures that encourage behaviours and measures that protect the environment, the relation between these fields is imperfect. He stresses the need to design a curriculum adapted to the peculiarities of a society characterised by existential risk.

In her turn, Anette Gough, in her study Mutualism: A different agenda for environmental and science education (2002), believes that professionals in the field of education, as well as specialists in environmental protection, must rethink their relationship. "The rhetorical reality gap between general statements on the importance of implementing environmental education into educational sciences and the results of the Curriculum presented in documents, as well as the distance between the contents taught by teachers and the students' interests raise again the spectrum of educational sciences at a limited level for environmental protection."

The meaning of the role of the direct connection with the natural world becomes even more obvious upon simply noticing a peak in children's interests in classes where they study disciplines with specialised laboratories: biology, physics, chemistry, geography. Presence in a context that is different from the daily one (classroom) and contact with experimentation imply activating some important psychological indicators: sustained attention for longer time, a wish to be involved in the organised activities and work in a team, enhanced motivation, interest, and creativity, and general content expressed in various ways. Logically, there follows that in the training process, the experience acquired from the direct interaction with a subject (in its entire context) acts as an integrator, completing and bringing consistency to the training process. This is the simplest way to help students broaden their horizon, building a general perspective to the detriment of a vision limited by strictly theoretical acquisitions. This way, nature generously opens to the study. 
Education as an element enhancing individual and collective awareness of the need to preserve the environment 85

\section{BENCHMARKS OF INFORMAL EDUCATION IN THE FIELD OF ENVIRONMENTAL EDUCATION}

Educational resources for the configuration and consolidation of awareness in relation to respect for the environment must be capitalised upon starting from early childhood.

As a method used to acquire skills, habits, capabilities based on observations as well as concrete actions through contact with the surroundings, informal education plays an integrating role at the level of the results obtained in forming behaviours, in contrast with the information transmitted via verbal or written means. Human values such as empathy, tolerance, understanding, sacrifice, the ability to adapt to rough situations, and receptiveness are enhanced by this type of education.

Starting from simple gestures, such as training the child in treasuring and appreciating a well-cared family space, cultivating elementary habits - for instance, from removing and depositing various waste types in the designated areas around the house, to developing a critical view on any non-compliance with the rules for preserving cleanliness inside and outside the house, for example in public playgrounds, etc., it is possible to lie an authentic educational foundation for later acquisitions under the same objective. Subsequently, the formal education system will be enabled to continue the process, if, of course, it was appropriately initiated within the family, with the conjugated effort of the two institutions, family and school.

According to P. Bell (2009), informal education can be described as the type of education in which the subject (the student) must be motivated, interested in acquiring knowledge in a voluntary, personal, continuous, contextual, relevant, and collaborative manner, uninterruptedly and with an open mind towards novelty. It is considered that informal education has the advantage that it can be accessed by people of various ages, as it addresses various learning styles (H. Eschach, 2007).

In informal education, educational values are transmitted in the absence of an organised framework, which functions following pre-established rules. Smith (2009) considers informal education as the style of "learning that occurs every day of our life". Practically, the informal component of education is translated through the continuous learning process, respectively one that takes place every day during a person's life, and which can spring from the daily experience acquired in one's family, circle of friends, or from the media, from nature, together with any other sources of influence from the person's environment.

As best defining the method through which an individual acquires knowledge during his entire existence, one's childhood, characterised as the stage of the great acquisitions with a role in the crystallisation of human personality, remains the most important stage, in relation to informal education. 
As a stage of life characterised by untainted receptiveness, openness, and thirst for knowledge, we can speak of a permissive context for acquisitions through discovery and curiosity. Cultivating human values that are important for modelling one's personality must be supported, besides the set of norms and socially acceptable behavioural rules, by the child's connection with the natural world. Beyond the sensitisation of the affective side through contact with a pet, for instance, which is of undisputed importance through the effects it generates, a child can also be taught to appreciate the beauty of a flower, of a sunset, of a tree in bloom, the green and cold of a forest, the clear waters of a spring, etc. - thus developing a more balanced behaviour, better thought attitudes, and becoming more aware both in relation to themselves and with their surroundings. Directly exploring the natural environment creates a favourable context for developing the child's authentic emotional connection with it, and gives him a better perception of the world he lives in.

In this existential timespan when the foundation is laid for the later adult, the means that can contribute to education in the spirit of the virtues that must define humankind (wisdom, justice, courage, self-control, love, positive attitude, tenacious labour, gratitude, modesty) abound in number and diversity. In this sense, attributing tasks, from simple, domestic ones, until encouraging the child to get involved in voluntary actions of different kinds, including, or mainly those related to environmental protection, make the child more responsible, form and educate him, generate beneficial changes in his mind and behaviour. Additionally, merging informal education with the education transmitted in a formal framework will occur naturally.

Involving the child in stimulating contexts such as the ones mentioned above enhance his motivation, increasing his interest and will to fulfil a certain responsibility, while experiencing the feeling of such approaches. For example, participating in social initiatives with the aim to clear nature from waste, thus insuring a clean and healthy environment, complying with the recycling rules at home and in public places, repopulation of deforested areas through replanting actions, and so on, all have unsuspected beneficial results on the individual, with bilateral advantages.

We can say that the indispensable nature of the process of education in such contexts is not necessary a new idea. Since always, humankind has aspired to train their children in the spirit of moral values, goodwill, responsibility for their own actions, etc. The accent placed stronger than ever on the need to raise responsible generations, aware of the importance of the care towards the environment, is justified by the threateningly fragile state that this existential space has reached.

All these arguments point to the need to strongly integrate environmental protection within both forms of education - informal and formal - a need where it 
is necessary to identify the ways in which environmental problems can be solved "in peace" with the phenomenon of accelerated digitalisation. In this respect, the adoption of appropriate didactic and pedagogical strategies, where interests and concerns with environmental issues would hold an important and well-deserved place, is a major benchmark on the mainly theoretical line of current approaches.

As a component of undisputed significance for humankind nowadays, technology generates insufficient results in the direction of environmental and respectively economic issues. From the perspective of harmonising economy with ecology, environmental education can provide the necessary support to insure a compatible, optimal, and desirable environment. In the opinion of J. C. Smyth (2006), combining economic development with environmental management is an approach whose effects have a positive impact on environmental education. In other words, placing an accent on this educational component can, in the author's view, insure indeed a harmonious relationship between economy and nature.

\section{CONCLUSIONS}

Man's attack on nature in all forms (pollution, deforestation, reckless usage of the planet's resources, and disturbance of the biosphere as a whole) must raise a proportional interest to the level of seriousness of the situation from institutional decision-makers, who are authorised to generate modifications in the school programmes in agreement with the requirements of the current situation.

The gap between the theoretical contents and the position of the individual in the actual context in which a phenomenon, event, or situation occurs determines individuals to draw significant knowledge has an unwanted effect on the expectation for man to be in the position to effectively approach the issue of preserving his environment.

Integrating environmental education in the learning process, identifying the triggers that allow unifying the informal and non-formal into the formal dimension, are a major concern for the academic bodies and specialists in the field.

\section{Bibliography}

1. Dori, Y., J., Tal, R., T. (2000). "Formal and Informal Collaborative Projects: Engaging in Industry with Environmental Awareness.", in Science Education, volume 84, n.1, pp.95-113.https://doi.org/10.1002/(SICI)1098-237X(200001)84:1<95::AIDSCE7>3.0.CO;2-W

2. Dolan, T., Nichols, B., \& Zeidler, D. (2009). "Using Socio-Scientific Issues in Primary Classrooms.", in Journal of Elementary Science Education, 21, pp.1-12. 
3. Heimlich, J., E. (1993). "Nonformal Environmental Education: Toward a Working Definition.”, Columbus, OH: ERIC Clearinghouse for Science, Mathematics and Environmental Education.

4. Hadzigeorgiou, Y. \& E. Stivaktakis, (2008). "Encouraging involvement with school science", in Journal of Curriculum \& Pedagogy, 5, pp. 138-162. https://doi.org/10.1080/15505170.2008.10411692

5. Pugh, K.,J. (2004). "Newton's laws beyond the classroom walls" in Science Education, 88, pp. 182-196. https://doi.org/10.1002/sce.10109

6. Ashley, M. (2000). "Science: an unreliable friend to environmental education?" in Environmental Education Research, 6, pp. 269-280. https://doi.org/10.1080/713664678

7. Gough, A. (2002) "Mutualism: a different agenda for science and environmental education." in International Journal of Science Education, 24, pp. 1201-1215. https://doi.org/10.1080/09500690210136611

8. Bell, P., Lewenstein, B., Shouse, A., W., Feder, M., A., (Editors). (2009). National Research Council. Learning Science in Informal Environments: People, Places, and Pursuits. Washington, DC: The National Academies Press.

9. Eschach, H. (2007). "Bridging In-school and Out-of-school Learning: Formal, NonFormal, and Informal Education" in Journal of Science Education and Technology, Volume 16, Issue 2, pp.171-190. DOI: 10.1007/s10956-006-9027-1

10. Smith, L., Clayton, B. (2009) "Recognising Non-Formal and Informal Learning: Participant Insights and Perspectives." A National Vocational Education and Training Research and Evaluation Program Report, ERIC, Number ED507128.

11. Smyth, J., C. (2006). "Environment and Education. A view of changing scene" in Environmental Education Research, 12 (3-4), pp.247-264. https://doi.org/10.1080/13504620600942642

12. https://www.epa.gov/education/what-environmental-education

13. https://www.epa.gov/sites/production/files/documents/neea.pdf

14. https://files.eric.ed.gov/fulltext/ED507128.pdf

(C) 2020 by the authors. Licensee UAIC, Iasi, Romania. This article is an open access article distributed under the terms and conditions of the Creative Commons Attribution (CC BY-NC-ND) license (https:// creativecommons.org/licenses/by-nc-nd/4.0). 